\title{
A social constructivism framing of mobile pedagogy in english language teaching in the digital era
}

\author{
Zhang Jie ${ }^{1}$, Marlia Puteh ${ }^{2}$, Nurhasmiza Abu Hasan Sazalli ${ }^{3}$ \\ ${ }^{1}$ Faculty of Social Sciences \& Humanities, Universiti Teknologi Malaysia (UTM), Malaysia \\ School of Foreign Languages and Cultures, North Minzu University, China \\ ${ }^{2,3}$ Faculty of Social Sciences \& Humanities, Universiti Teknologi Malaysia (UTM), Malaysia
}

\begin{tabular}{l}
\hline Article Info \\
\hline Article history: \\
Received Jan 12, 2020 \\
Revised Mar 15, 2020 \\
Accepted Apr 19, 2020 \\
\hline
\end{tabular}

\section{Keywords:}

Digital era

English language teaching

Mobile pedagogy

Social constructivism

\begin{abstract}
Social Constructivism is elaborated as a theoretical background to support modern pedagogy with mobile technology in the digital age. Studies of theories and framework in terms of mobile pedagogy are combed up to find its connection between language teaching and Social Constructivism. Four theoretical framework of mobile pedagogy are listed in this paper to establish the link with Social Constructivism. The analysis of the Zone of Proximal Development from Social Constructivism theory indicates that mobile pedagogy, integrated with technology, pedagogy and subject content, is student-driven model which needs teacher's guidance in the level that students cannot scaffold knowledge on their own. Teachers have to update pedagogical concept with enhanced technological knowledge for the demand of education in the digital era.
\end{abstract}

Copyright $@ 2020$ Institute of Advanced Engineering and Science. All rights reserved.

\section{Corresponding Author:}

Zhang Jie,

Faculty of Social Sciences \& Humanities,

Universiti Teknologi Malaysia (UTM), Malaysia.

Email: 80527410@qq.com

\section{INTRODUCTION}

Social Constructivism perceives learning as an active process and negation between cultures, which can be regarded as an effective paradigm to incorporate collaboration and interactions [1]. Social Constructivism is one of the key concepts in the works of Lev Vygotsky [2]. It emphasizes the social environments and interpersonal connections in the process of educational activities, which are central components to construct knowledge in mobile pedagogy. Social Constructivism theory supports the theoretical foundation for mobile pedagogy in that knowledge is based on the experience of the learners. It promotes student-centred mode, collaborative interaction and situated learning in the changing dynamic information environment.

Mobile pedagogy is the philosophy or framework to guide teachers in adopting mobile learning online or offline [3]. As mobile learning has the features as mobility in physical space, conceptual space, social space, time and technology [4], the pedagogy of mobile learning needs to study how contribution can be made with the convenience of space and technology in the process of acquiring knowledge and skills. Mobile pedagogy stresses the importance on learners because learners are responsible for the time and space, which "enables new forms of Social Constructivist pedagogy within a variety of course contexts" [5].

This article is aimed to bring the connection that exists in mobile pedagogy and Social Constructivism. Data is presented from four selected theoretical studies to implicate the theory of Social Constructivism for mobile pedagogy in language teaching. With a focus on teachers' pedagogical shift in the information ecosystem, this study throws light on Social Constructivism to study mobile pedagogy in education. 


\section{THEORETICAL BACKGROUND AND LITERATURE REVIEW}

Social Constructivism extends constructivism by incorporating the role of social environment and cultural artefact in the process of acquiring knowledge [6]. The Zone of Proximal Development [7] describes the spheres that learners can do and that learners cannot do in their learning process. The core circle is the learner's autonomy learning without the help from teachers. The educators' role to guide students is in the middle and outside circle. It shows that students can acquire knowledge on their own at a lower level, but students need teachers' guidance at a higher level. This builds strong theoretical foundation for mobile pedagogy that mobile learning occurs in students' autonomous learning, but teachers' role is more important to guide students to generate learning and explore knowledge in the high level of learning, as is shown in Figure 1.

Based on the concept of the Zone of Proximal Development, the author designs Figure 2, which indicates the role of teachers in the Zone of Proximal Development. Mobile pedagogy takes place when learners need guidance and advice beyond their learning ability.

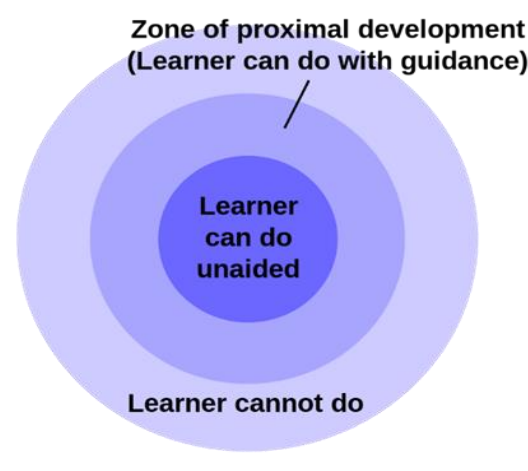

Figure 1. The Zone of Proximal Development (Vygotsky, 1978)

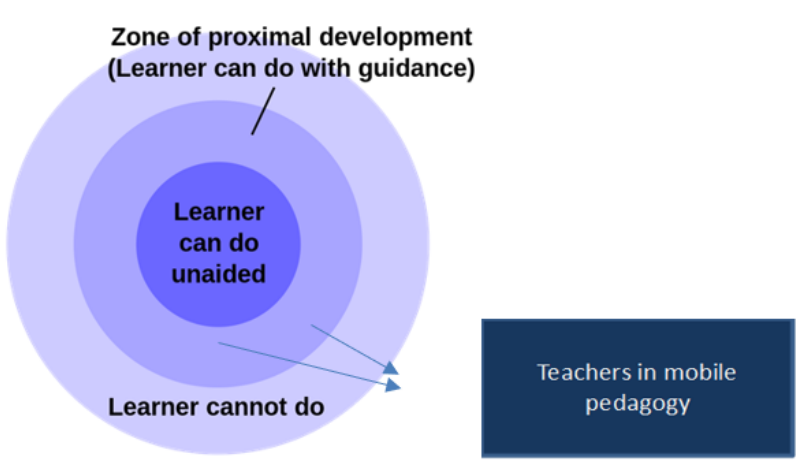

Figure 2. Mobile Pedagogy in the Zone of Proximal Development (Adapted from Vygotsky, 1978)

The Zone of Proximal Development supports the notion that teachers are in the outside spheres as facilitators to guide students when knowledge is beyond students' understanding, which is the main concept of mobile pedagogy that teachers supervise students when students need assistance for inquiries [8]. In addition, social cultural factors are considered in Social Constructivism that the learning process involves "the internalization of cultural forms of behaviour involves the reconstruction" [2]. It indicates the important role of cultural mediation in the interactive communication.

\section{CASE STUDIES}

Four studies regarding mobile pedagogy are selected to show the recent research on pedagogical framework in the digital era. Social Constructivism is applied to provide theoretical support in enhancing education with information and communication technology.

\subsection{A pedagogy-space-technology framework}

The Pedagogy-Space-Technology Framework is conducted by professor Radcliffe in 2009 [9]. It guides the learning process across spaces in terms of pedagogy, space, technology and their relationship. By examining the connection with pedagogy, space and technology, the Pedagogy-Space-Technology framework proposes an inquiry of the education of information technology in the digital era [10]. The relationship between pedagogy, technology and space is shown in Figure 3.

As shown in Figure 3, space and technology are two important factors in mobile pedagogy. Pedagogy is extended by technology in terms of space and time with the mobility afforded by mobile devices, while technology supports distance learning with technology-assisted education delivery. Space inspires pedagogy with various teaching models including online learning and blended learning, such as Massive Open Online Class (MOOC), Small Private Online Class (SPOC) and Mobile-assisted Language Learning (MALL) with student-driven design. Space comprises physical space, conceptual space and social space [4], which means that learners are motivated to study according to their own interest in various social groups without any limitations of locations. Mobile pedagogy regards learners as stakeholders in leading them to the self-directed learning that aligns with their needs [11]. The Pedagogy-space-technology Framework integrates pedagogical intent, technological factors and operational practices into student-driven oriented model in the education of the digital era. 


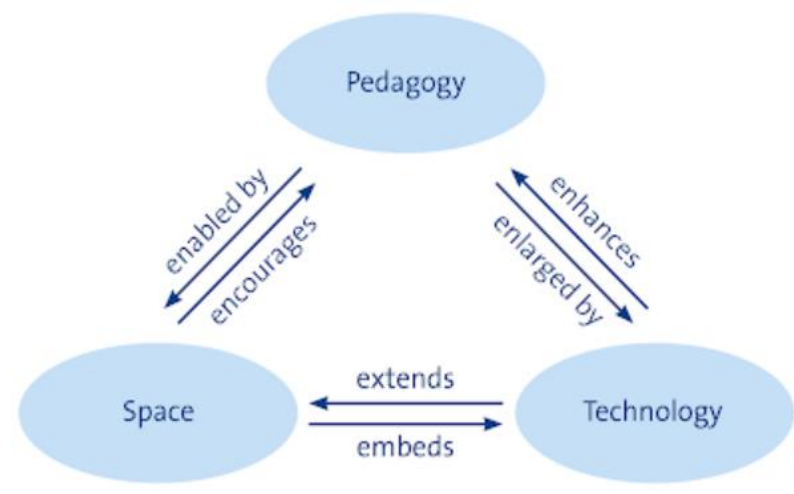

Figure 3. A Pedagogy-space-technology Framework (Adopted from Radcliffe D. 2009)

\subsection{Koole's FRAME model}

Koole [12] proposed rational analysis for mobile education, shown in Figure 4. It covers three aspects in terms of English as a foreign language learning (EFL) in digital era: device (mobile technology), learner (language learners in the digital era) and social (social interaction and online resources). Therefore, EFL with mobile technology is carried out effectively in formal and informal settings with the features of the intersection in those three aspects $[13,14]$.

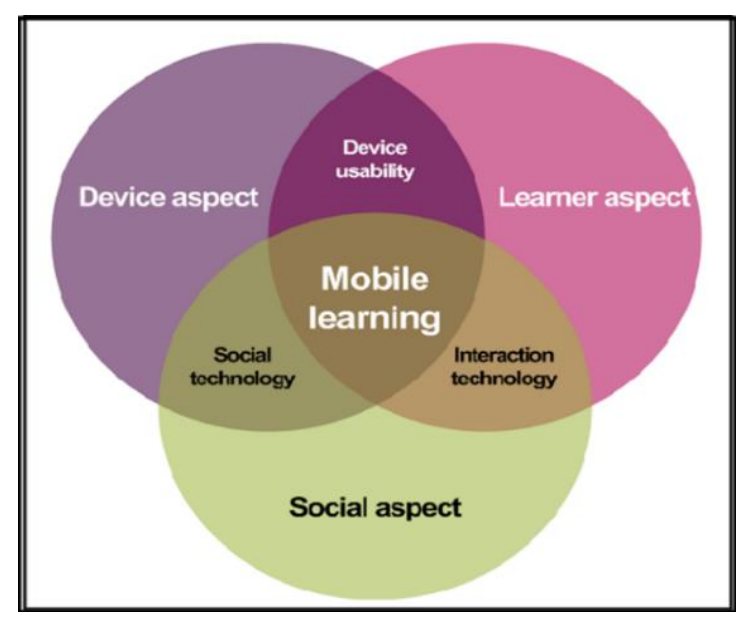

Figure 4. Koole’s FRAME Model (M. L. Koole, 2009)

The three circles represent the aspects of device, leaner and social environment. The overlapped part contains the attributes of both aspects. The intersected core in the centre, which is the occurrence of mobile learning, is the ideal situation of mobile learning in digital era. Thus, practitioners utilize knowledge of mobile technology, social and cultural environments and leaners' capacities to effect mobile educational activities. Accordingly, mobile pedagogy in teaching English as a foreign language needs the integration of these three aspects to enhance teaching and learning.

\subsection{Technology pedagogical content knowledge model}

Technology Pedagogical Content Knowledge Model (TPACK) integrates teaching with mobile learning for an effective teaching in digital education. TPACK comes from PCK (Pedagogical Content Knowledge), a framework proposed by Shulman in 1986 [15], which describes knowledge construction that teachers possess and use for their professional understanding. TPACK [16] extends Shulman's concept of PCK with a focus on technology and the interaction based on the technological promotion in education. TPACK model is displayed in Figure 5. 


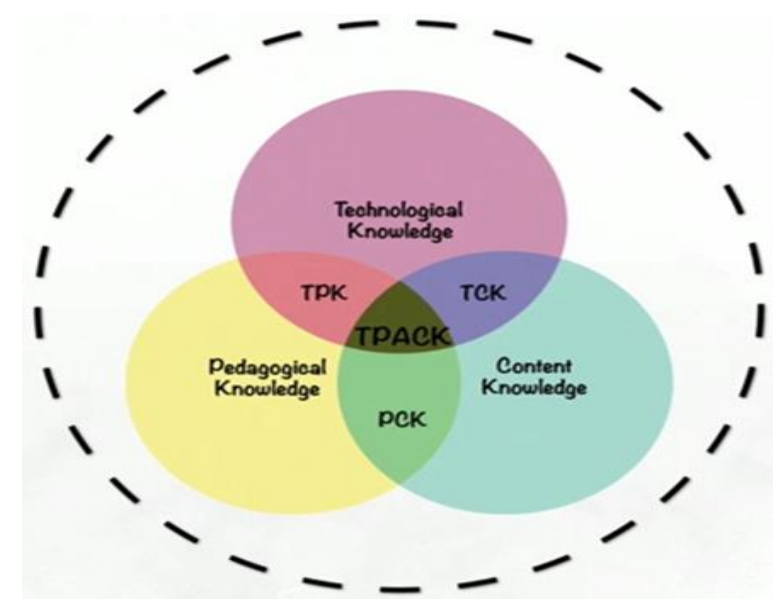

Figure 5. TPACK Model (adapted from Mishra \& Koehler, 2008)

TPACK model is to identify the nature of knowledge that teachers need to incorporate into mobile pedagogy, but the complexity, multi-disciplinary and blurred interrelations of teacher knowledge draw relative criticisms [17-19]. Based on "the belief that teachers and learners are active participants in making and shaping language learning" [20], Agnes designed a Pedagogical Framework for Mobile-assisted Language Teaching and Learning, as shown in Figure 6.

\subsection{A pedagogical framework for mobile-assisted language teaching and learning}

Four aspects are covered in the framework of mobile pedagogy in teaching EFL: teacher wisdom, device features, language dynamics and learner mobilities. Among these four aspects, teacher wisdom is a new concept proposed in the digital era. It refers to teacher's pedagogy which is influenced by academic background, working experience and understanding of technology, inclusive of pedagogical methods and strategies to guide students in the learning. Alexander [21, 22] defined pedagogy as "the observable act of teaching together with its attendant discourse of educational theories, values, evidence and justifications".

In extending the ability to improve mobile pedagogy, teachers need to enhance the knowledge in these four aspects. Integrated knowledge with the four sections for an effective approach in teaching is thus important. To achieve this, the integration of intersected knowledge in multidisciplinary subjects is essential to develop teachers' "technological, pedagogical and content knowledge" [23] in teachers' professional development.

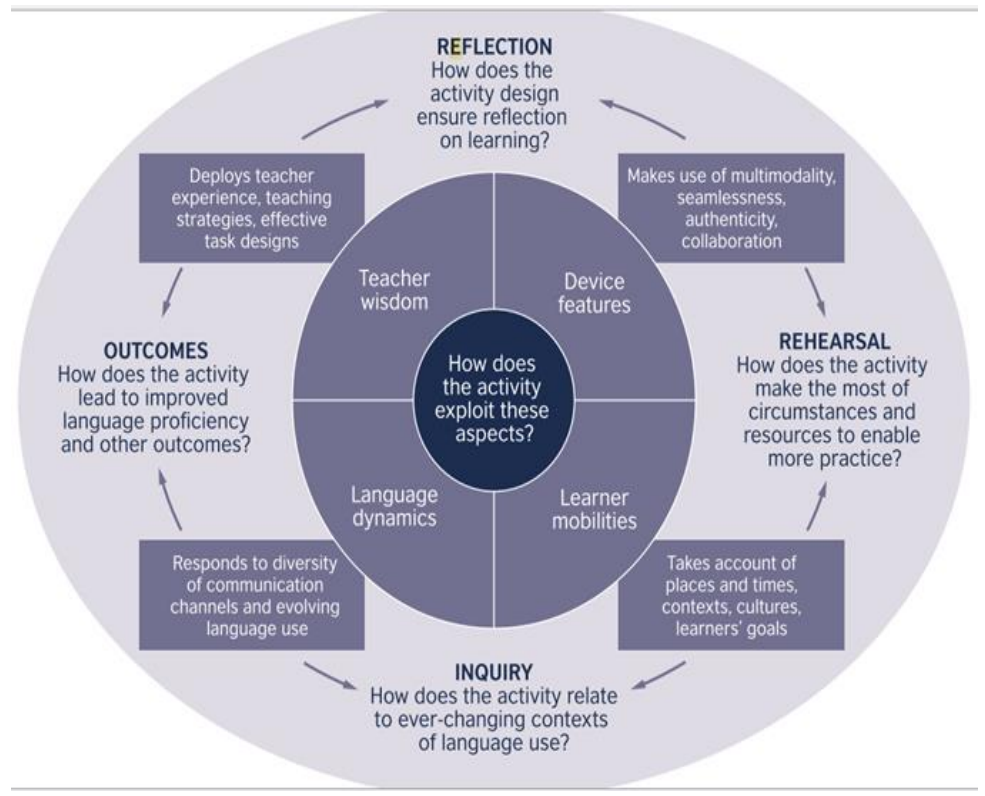

Figure 6. A Pedagogical Framework for Mobile-assisted Language Teaching and Learning (Kukulska-hulme et al., 2015. p 8) 


\section{RESULT}

Based on the framework above, mobile pedagogy adds technology to pedagogical conception, by which extends the educational theories, values and justifications to teaching with the new concept of mobile technology. In the digital education, teachers have the responsibility to get prepared for a change to guide students in the implementation of mobile educational teaching and activities [22]. Social Constructivism is developed from constructivism, which emphasized the important role of students. It adds social factors and culture into the learner's cognitive learning $[1,2]$. Learners' role is emphasized in the progress of scaffolding. Therefore, learners take responsibility for their learning in acquiring new knowledge. Technology is the catalyst for the integration of education to break operational constraints [24]. Language teaching meets Social Constructivism in enhancing authentic language environment and raising contextual awareness. The fundamental concept of mobile pedagogy is derived from Social Constructivism that educational activities occur in the process of continual development in scaffolding knowledge through practices within a specific cultural community. Therefore, Social Constructivism provides theoretical foundation to support teachers to adopt mobile pedagogy in digital era.

\section{DISUCSSION}

Based on Social Constructivism, the pedagogical shift of mobile pedagogy is that teachers facilitate students to inquire knowledge in a student-centred model for knowledge reconstruction. The elements for mobile pedagogy adoption include teachers' perception on mobile pedagogy, the background of mobile pedagogy, the theory of ZPD. The components of mobile pedagogy draw the idea from TPACK, which consists of three elements, i.e. technological knowledge, pedagogical knowledge and content knowledge. Technological knowledge is the technical skills of technology, including network information, social media and application skills for the utility of mobile devices. Pedagogical knowledge is the pedagogical knowledge used in teaching, including student-centred pedagogy based on Social Constructivism and teachers' wisdom on mobile pedagogy. Content knowledge refers to the subjects and contents, which allow teachers to teach in a specific area with academic background. Teachers' roles in mobile pedagogy is mainly to scaffold knowledge in the process of learning and teaching. Teachers' professional development denotes teacher's sustained lifelong learning for the improvement of their professional knowledge in teaching career. It is important to support teachers with effective pedagogical and technological knowledge to facilitate effective teaching [25]. Teachers' education training is the main program to support teachers with continuous and supportive training for teachers' professional development. ZPD Theory based on Social Constructivism provides theoretical support for mobile pedagogy in the process of scaffolding knowledge during the process of teaching and learning with mobile technology.

\section{CONCLUSION}

This article presented the theory of Social Constructivism with the Zone of Proximal Development to elaborate mobile technology in the digital era. It analyses the close link between Social Constructivism and mobile pedagogy, which provides theoretical support for language teaching in the digital era. Further study should focus on how teachers enhance knowledge and skills to enrich the pedagogy with educational technology and information integration.

\section{ACKNOWLEDGEMENTS}

This research is funded by Ningxia Provincial Higher Education Teaching Reform Project "Research on How to Use Mobile Learning to Teach English in MOOC Model" (NXJG2017060).

\section{REFERENCES}

[1] Churcher, K., Downs, E., \& Tewksbury, D. "Friending" Vygotsky: A Social Constructivist Pedagogy of Knowledge Building Through Classroom Social Media Use. Journal of Effective Teaching, vol. 14, no. 1, pp. 33-50, 2014. https://doi.org/10.1007/s11096-009-9327-7

[2] Vygotsky, L. "Mind in Society." Harvard University Press, 1978.

[3] Baxter, R., Hastings, N., Law, A., \& Glass, E. J. "Mobile Pedagogy is Pedagogy of the XXI Century". Animal Genetics, vol. 39, no. 5, pp. 561-563, 2008.

[4] Sharples, M., Milrad, M., \& Vavoula, G. N. "Mobile Learning: Small devices, big issues." Technology-Enhanced Learning: Principles and Products, May 2014. https://doi.org/10.1007/978-1-4020-9827-7

[5] Cochrane, T. D. "Critical success factors for transforming pedagogy with mobile Web 2.0." British Journal of Educational Technology, vol. 45, no. 1, pp. 65-82, 2014. https://doi.org/10.1111/j.1467-8535.2012.01384.x

[6] Kanselaar, G., Jong, D., Jong, D., \& Group, T. “Constructivism and socio-constructivism”, pp. 1-7, 1986. 
[7] Chaiklin, S. "The zone of proximal development in Vygotsky's analysis of learning and instruction". In Vygotsky's educational theory and practice in cultural context. Cambridge University Press, 2003.

[8] Cook, E. "The future of mLearning begins with a baseline pedagogy." Internet Learning, vol. 4, no. 2, pp. 25-36, 2015.

[9] Radcliffe, D. "A pedagogy-space-technology (PST) framework for designing and evaluating learning places." In Learning spaces in higher education: Positive outcomes by design. Proceedings of the Next Generation Learning Spaces 2008 Colloquium, University of Queensland, Brisbane, pp. 11-16, 2009.

[10] Radcliffe, D., Wilson, H., Powell, D., \& Tibbetts, B. "Designing next generation places of learning: Collaboration at the pedagogy-space-technology nexus." The University of Queensland, pp. 1-20, 2008. Retrieved from www.uq.edu.au/nextgenerationlearningspace/

[11] Ng, J. "Innovating with Pedagogy-Space-Technology (PST) Framework." The Online Moot Court, pp. 52-65, 2015.

[12] Koole, M. L. "Mobile Learning-A Model for Framing Mobile Learning." Mobile Learning: Transforming the Delivery of Education and Training, vol. 1, no. 2, pp. 25-47, 2009.

[13] Koole, S. L. "The psychology of emotion regulation: An intergrative review." Cognition \& Emotion, vol. 23, no. 1, pp. 4-41, 2009. https://doi.org/10.1080/02699930802619031

[14] Leow, C. K., Ahmad, W., Wan, J., \& Samsudin, Z. "Mobile-Assisted Second Language Learning: Developing a Learner-centered Framework." International Conferences on Education Technologies, pp. 27-34, 2014.

[15] Shulman, L. S. S. "Those Who Understand: Knowledge Growth in Teaching." Educational Researcher, vol. 15, no. 2, pp. 4-14, 1986. https://doi.org/10.3102/0013189X015002004

[16] Mishra, P., \& Koehler, M. J. “Introducing Technological Pedagogical Content Knowledge.” In Annual Meeting of the American Educational Research Association, pp. 1-16, March 2008.

[17] Chang, Y., Jang, S., \& Chen, Y. “Assess university students' perceptions of their Physics instructors' TPACK development in two contexts." British Journal of Education Technology, vo. 46, no. 6, pp. 1236-1249. 2014. https://doi.org/10.1111/bjet.12192

[18] Dong, Y., Chai, C. S., Sang, G., Hwee, J., Koh, L., \& Tsai, C. "Exploring the Profiles and Interplays of Pre-service and In-service T eachers' Technological Pedagogical Content Knowledge (TPACK) in China." Educational Technology \& Society, vol. 18, no. 1, pp. 158-169, 2015.

[19] Graziano, K. J., Herring, M. C., Carpenter, J. P., Smaldino, S., \& Finsness, E. S. “A TPACK Diagnostic Tool for Teacher Education Leaders.” TechTrends, vol. 61, no. 4, pp. 372-379, 2017. https://doi.org/10.1007/s11528-017-0171-7

[20] Kukulska-hulme, A., Norris, L., \& Donohue, J. "Mobile pedagogy for English language teaching: a guide for English language teaching. The British Council, London, 2015. https://doi.org/10.1007/s00464-015-4135-8

[21] Alexander, R. (2005). Education, Culture and Cognition: intervening for growth International Association for Cognitive Education and Psychology. In 10th International Conference, University of Durham, UK. https://doi.org/10.4135/9781446279526.n6

[22] Rooyen, C. Van. "A socially just pedagogy in the use of mobile devices in higher education? The case of Humanities first-year students at a South African university." SOTL in the South, vol. 2, no. 2, pp. 53-70, 2018.

[23] Maor, D. "Using TPACK to develop digital pedagogues: a higher education experience." Journal of Computers in Education, vol. 4, no. 1, pp. 71-86, 2017. https://doi.org/10.1007/s40692-016-0055-4

[24] Kothari, P., \& Chatterjee, A. "Education 3 . 0 and beyond : A learner-led experience of Education." Proceedings of the 22nd International Conference on Computers in Education, 2014.

[25] Gunter, G. A., \& Reeves, J. L. "Online professional development embedded with mobile learning : an examination of teachers' attitudes, engagement and dispositions." British Journal of Educational Teaching, vol. 48, no. 6, pp. 1305-1317, 2016. https://doi.org/10.1111/bjet.12490

\section{BIOGRAPHIES OF AUTHORS}
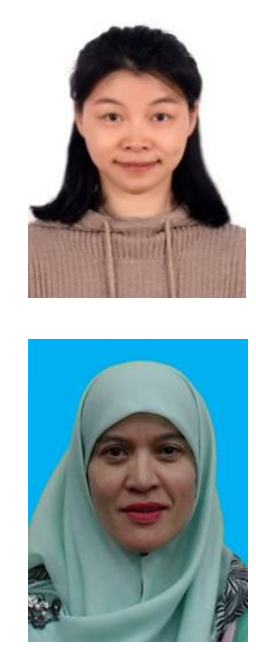

Zhang Jie, Ph.D in Universiti Teknologi Malaysia. Associate Professor from North Minzu University, Ningxia, China. Research areas include mobile learning, distance teaching and learning, second language acquisition and English for Specific Purpose.

Marlia Puteh, Associate Professor in Faculty of Social Sciences \& Humanities, Universiti Teknologi Malaysia Kuala Lumpur. Publications include refereed journals, conference papers, book chapters and academic books in the domains of English language studies, engineering education, technology in language learning, higher education policies and disruptive challenges in higher education. Academic Expertise in Higher education policy research, Engineering education research, English language studies, Cross-cultural communication research and Webbased teaching \& learning. 


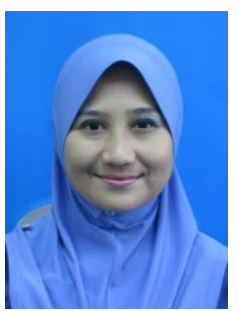

Nurhasmiza Abu Hasan Sazalli, lecturer in Faculty of Social Sciences \& Humanities, Universiti Teknologi Malaysia, Kuala Lumpur. PhD in Education from University of Exeter, United Kingdom. Areas of specialization are mobile learning, Design Based Research (DBR), second language acquisition, 21st century learning and web 2.0 tools for teaching and learning 